\title{
COMPARISON OF DOXYCYCLINE AND AZITHROMYCIN FOR THE TREATMENT OF SCRUB TYPHUS IN CHILDREN
}

\author{
Natarajan Pachiappan1, Bahubali D. Gane ${ }^{2}$ \\ ${ }^{1}$ Associate Professor, Department of Paediatrics, Sri Venkateshwara Medical College and Research Centre, Ariyur, Pondicherry. \\ ${ }_{2}^{2}$ Assistant Professor, Department of Paediatrics, Sri Venkateshwara Medical College and Research Centre, Ariyur, Pondicherry.
}

\section{ABSTRACT}

\section{BACKGROUND}

Scrub typhus is an acute, febrile, infectious illness that is caused by Orientia tsutsugamushi. Doxycycline is a best choice of initial antimicrobial treatment for scrub typhus. The other alternative drug is azithromycin. We conducted this study to compare the efficacy and adverse effects of both the drugs.

\section{METHODS}

This is a retrospective study done in tertiary care hospital. Study was done with aim to compare the efficacy and side effects of doxycycline and azithromycin for the treatment of scrub typhus. Cases from December 2011 to November 2015, satisfying inclusion criteria were included. The primary efficacy outcome was the time to defervescence. The secondary efficacy outcome analysed were treatment failure, relapse and adverse effects. Appropriate statistical tests were used to analyse the data.

\section{RESULTS}

One hundred and seven children were included in the study. There were 67 cases in the doxycycline treated group and 40 cases in the azithromycin group. Baseline characters were similar among both groups. Both antibiotic regimens were highly effective for the treatment of scrub typhus. Fever subsided early in the children who received doxycycline. There were no relapses in either group.

\section{DISCUSSION}

Both drugs were equally effective. Our study suggested that azithromycin was better tolerated than doxycycline. Gastrointestinal adverse events were lesser with azithromycin but statistically not significant.

\section{KEYWORDS}

Scrub Typhus, Doxycycline, Azithromycin, Defervescence.

HOW TO CITE THIS ARTICLE: Pachiappan N, Gane BD. Comparison of doxycycline and azithromycin for the treatment of scrub typhus in children. J. Evolution Med. Dent. Sci. 2016;5(20):998-1000, DOI: 10.14260/jemds/2016/232

\section{INTRODUCTION}

Scrub typhus is an acute, febrile, infectious illness that is caused by Orientia tsutsugamushi. 0 . tsutsugamushi includes heterogeneous strains classified in five major serotypes: Boryon, Gilliam, Karp, Kato and Kawazaki.[1] Chigger mites act as the primary reservoirs for 0 . tsutsugamushi. Once they are infected in nature by feeding on the body fluid of small mammals, including the rodents, they maintain the infection throughout their life stages and, as adults, pass the infection on to their eggs in a process called transovarial transmission. Similarly, the infection passes from the egg to the larva or adult in a process called transstadial transmission. In this way, chigger mite populations can autonomously maintain their infectivity over long periods of time.[2]

Scrub typhus is more common in 'tsutsugamushi triangle', which includes the areas of India, Pakistan, and Nepal in the west, to south-eastern Siberia, Japan, China and Korea, Indonesia, the Philippines, and northern Australia.[3,4] Doxycycline is a best choice of initial antimicrobial treatment for scrub typhus.

Financial or Other, Competing Interest: None.

Submission 11-02-2016, Peer Review 25-02-2016,

Acceptance 27-02-2016, Published 08-03-2016.

Corresponding Author:

Dr. Bahubali D. Gane,

Assistant Professor,

Department of Paediatrics,

Sri Venkateshwara Medical College \& Research Centre,

Ariyur, Pondicherry.

E-mail: bahubaligane@gmail.com

DOI: $10.14260 /$ jemds/2016/232
Some cases of resistance have been reported from Thailand. ${ }^{[4]}$ The other alternative drug is azithromycin. We conducted this study to compare the efficacy and adverse effects of both the drugs.

\section{MATERIALS AND METHODS}

This is a retrospective study done in tertiary care hospital. Study was done with aim to compare the effect and side effects of doxycycline and azithromycin for the treatment of scrub typhus. Cases from December 2011 to November 2015 were included. Patients included in study are: confirmed to have scrub typhus with a positive Scrub Typhus IgM ELISA test and presence of eschar, Children less than 18 years. Data collected regarding clinical profile of cases. This study was approved by the Institute research and ethical committee and patient confidentiality was maintained using unique identifiers. The primary efficacy outcome was the time to defervescence. The secondary efficacy outcome analysed were treatment failure, relapse and adverse effects.

Failure was defined as the persistence of fever without any identifiable cause. "Relapse" was defined as the reappearance of fever and clinical manifestations of scrub typhus, in the absence of any other identifiable cause, within 30 days after completing therapy. The data was analysed using Microsoft Excel 2010 and SPSS (Version 19) software. All data on categorical variables were presented as frequencies and percentages. Chi square test was used to compare the frequencies and percentages. All the statistical analysis were carried out at $5 \%$ level of significance and $p$ value $<0.05$ was considered significant. 


\section{RESULTS}

One hundred and seven children were diagnosed to have scrub typhus during the study period. The cases were divided in to two groups according to antibiotic prescribed.

There were 67 cases in the doxycycline treated group and 40 cases in the azithromycin group. The dosage of doxycycline was $5 \mathrm{mg} / \mathrm{kg}$ per day in two divided doses for 7 days.

Dosage for azithromycin was $10 \mathrm{mg} / \mathrm{kg}$ per day for 5 days. Baseline characters are given in the Table 1 . There was no statistically significant difference between these two groups. Median age was 7 years among both the group. Duration of fever at the time of initiation of treatment was 6 days. Both antibiotic regimens were highly effective for the treatment of scrub typhus (Table 2). On the analysis of outcome, fever subsided early in the children who received doxycycline (Table 2). Time period from initiation of treatment to defervescence was 21 hours in doxycycline and 28 hours in azithromycin group. There were no relapses in either group. There were no deaths or serious adverse events in either group.

\begin{tabular}{|c|c|c|c|}
\hline Characters & $\begin{array}{c}\text { Doxycycline } \\
\text { Group } \\
\text { (n=67) }\end{array}$ & $\begin{array}{c}\text { Azithromycin } \\
\text { (n=40) }\end{array}$ & $\begin{array}{c}\mathbf{p} \\
\text { value }\end{array}$ \\
\hline $\begin{array}{c}\text { Gender } \\
\text { Male }\end{array}$ & 40 & 25 & $>0.05$ \\
Female & 27 & 15 & $>0.05$ \\
\hline Age & $7(1-13)$ & $7(2-14$ & $>0.05$ \\
\hline $\begin{array}{c}\text { Duration of } \\
\text { fever }\end{array}$ & $6(3-15)$ & $7(2-16)$ & $>0.05$ \\
\hline \multicolumn{3}{|c|}{ Table 1: Baseline Characters } \\
\hline
\end{tabular}

\begin{tabular}{|c|c|c|}
\hline Side Effects & $\begin{array}{c}\text { Doxycycline } \\
\text { Group } \\
\text { (n=67) }\end{array}$ & $\begin{array}{c}\text { Azithromycin } \\
\text { (n=40) }\end{array}$ \\
\hline Nausea & 9 & 5 \\
\hline Vomiting & 4 & 2 \\
\hline Diarrhea & 0 & 1 \\
\hline $\begin{array}{c}\text { Abdominal } \\
\text { discomfort }\end{array}$ & 2 & 2 \\
\hline \multicolumn{2}{|c|}{ Table 2: Comparison of Adverse Effects } \\
\hline
\end{tabular}

\begin{tabular}{|c|c|c|c|}
\hline & $\begin{array}{c}\text { Doxycycline } \\
\text { group } \\
\text { (n=67) }\end{array}$ & $\begin{array}{c}\text { Azithromycin } \\
\mathbf{( n = 4 0 )}\end{array}$ & $\begin{array}{c}\mathbf{p} \\
\text { value }\end{array}$ \\
\hline $\begin{array}{c}\text { Defervescence } \\
\text { Median (Range) }\end{array}$ & $21(2-72)$ & $28(4-82)$ & $>0.05$ \\
\hline $\begin{array}{c}\text { Fever } \\
\text { persistence } \\
\text { beyond 48 hrs }\end{array}$ & 4 & 2 & $>0.05$ \\
\hline $\begin{array}{c}\text { Relapse within } \\
\text { three months }\end{array}$ & 0 & 0 & $>0.05$ \\
\hline $\begin{array}{c}\text { Treatment } \\
\text { failures }\end{array}$ & 0 & 0 & $>0.05$ \\
\hline $\begin{array}{c}\text { Number of } \\
\text { adverse events. }\end{array}$ & 14 & 9 & $>0.05$ \\
\hline \multicolumn{2}{|c|}{ Table 3: Comparrision of out come } \\
\hline
\end{tabular}

\section{DISCUSSION}

Few years back it was rare in India. Now it has re-emerged in several states of India, which includes mainly Himachal Pradesh, Tamil Nadu, Karnataka, Jammu and Kashmir, Kerala, Maharashtra, Bihar, Rajasthan, West Bengal, Uttaranchal..[-7]
Various antibiotics useful for treating scrub typhus are tetracyclines, macrolides.[8] and fluroquinolones, specially ofloxacin, pefloxacin, ciprofloxacin.[9] Among tetracyclines commonly used drugs are Doxycycline and chloramphenicol. Effective macrolides are azithromycin, clarithromycin, roxithromycin. According to ICMR guidelines, Doxycycline is the drug of choice and dose is $5 \mathrm{mg} / \mathrm{kg} /$ day in two divided doses for 7 days. Use of tetracycline to treat children below 8 years is no longer a subject of controversy.[10,11] It has been observed that cosmetically perceptible staining of teeth require multiple courses of therapy. It has also been supported by American Academy of Pediatrics committee on infectious diseases.[12] Azithromycin is also a better drug for the treatment of scrub typhus as it effectively penetrates human polymorphonuclear leukocytes and macrophages, which are target cells for 0 . it also has been proven that Azithromycin is effective against various strains of 0 . tsutsugamushi. It can be given as short course as it has longer half-life.[13] Moreover, the in vitro effectiveness of azithromycin against various strains of 0. tsutsugamushi.[14]

We dint notice any relapses among the azithromycin and doxycycline group. Previous studies which used 7 days doxycycline therapy also noticed lesser relapse.[15] Our study suggest that azithromycin was better tolerated than doxycycline. Gastrointestinal adverse events were lesser with azithromycin but statistically not significant. Patients treated with doxycycline became afebrile early. Mean duration of defervescence for doxycycline group was 21 hours. Some of the earlier studies have shown contradictory results.[16] Azithromycin was better tolerated than Doxycycline but more costly.

\section{CONCLUSION}

Doxycycline and azithromycin were equally effective in the treatment of scrub typhus. Azithromycin is an appropriate alternative drug for treatment of scrub typhus.

Azithromycin was better tolerated than doxycycline but it is more expensive. Defervescence occurred early with doxycycline. Doxycycline can be used safely in children below 8 years also for short course.

\section{REFERENCES}

1. Tamura A, Ohashi N, Urakami H, et al. Classification of rickettsiatsutsugamushi in a new genus, orientia gen nov, as orientiatsutsugamushi comb nov. Int J Syst Bacteriol 1995; 45:589-591.

2. Seong $\mathrm{S}$, Choi M, Kim I. Orientiatsutsugamushi infection: overview and immune responses. Microbes and Infection 2001;3:11-21.

3. Panpanich R, Garner P. Antibiotics for treating scrub typhus. Cochrane Database Syst Rev 2009;CD002150.

4. Kelly DJ, Fuerst PA, Ching WM, et al. Scrub typhus: the geographic distribution of phenotypic and genotypic variants of orientia tsutsugamushi. Clin Infect Dis 2009;48:S203-30.

5. Mahajan SK, Rolain JM, Kashyap R, et al. Scrub typhus in Himalayas. Emerg Infect Dis 2006;12:1590-2.

6. Chrispal A, Boorugu H, Gopinath KG, et al. Scrub typhus: an unrecognized threat in south India-clinical profile and predictors of mortality. Trop Doc 2010;40:129-33.

7. Althaf A, Kumar KK, Suni KA, et al. A study on scrub typhus in a tertiary care hospital. Kuwait Med J 2008;3:11-4. 
8. Batra HV. Spotted fevers and typhus fevers in Tamil Nadu. Indian J Med Res 2007;126:101-3.

9. Claudid C, Laura S, Valentino FP, et al. Mediterranean spotted fever: clinical andlaboratory characteristics of 415 sicilian children. BMC Infect Dis 2006;6:60.

10. Siberry GK, Dumler JS. Rickettsialinfections. In: Kliegman RM, Behrman RE, Jenson HB, StantonBF, editors. Nelson textbook of pediatrics, 18th ed. Pennsylvania, Saunders, 2007;1289-1301.

11. Rikihisa Y, Ito S. Entry of rickettsia tsutsugamushi into polymorphonuclear leukocytes. Infect Immun 1982;38:343-5.

12. Martin DH, Mroczkowski TF, Dalu ZA. A controlled trial of asingle dose of azithromycin for the treatment of chlamydial urethritis and cervicitis. Azithromycin for chlamydial infections study group. $\mathrm{N}$ Engl J Med 1992;327:921-5.
13. Frenck RW Jr, Mansour A, Nakhla I, et al. Short-course azithromycinfor the treatment of uncomplicated typhoid fever in children and adolescents. Clin Infect Dis 2004;38:951-7.

14. Alvarez-Elcoro S, Enzler MJ. The macrolides: erythromycin, clarithromycin, and azithromycin. Mayo Clin Proc 1999;74:613-34.

15. Gladue RP, Bright GM, Isaacson RE, et al. In vitro and in vivouptake of azithromycin (CP-62,993) by phagocytic cells: possible mechanismof delivery and release at sites of infection. Antimicrob Agents Chemother 1989;33:277-82.

16. Olson JG, Bourgeois AL, Fang RCY, et al. Risk of relapse associatedwith doxycycline therapy for scrub typhus. In: Burgdorfer W, Anacker RL, eds. Rickettsiae and rickettsial diseases. New York: Academic Press, 1981;201-10. 